\title{
O MODELO DE DESENVOLVIMENTO DO TOCANTINS E O POVO AKWẼ-XERENTE: IMPACTOS SOCIOAMBIENTAIS E DESAFIOS DA INTERCULTURALIDADE
}

THE TOCANTINS DEVELOPMENT MODEL AND THE AKWẼ-XERENTE PEOPLE: SOCIO-ENVIRONMENTAL IMPACTS AND CHALLENGES OF INTERCULTURALITY

Reijane Pinheiro da Silva1
http://orcid.org/0000-0002-0636-9795
$\underline{\text { http://lattes.cnpq.br/0565922256384104 }}$

Héber Rogério Grácio² https://orcid.org/0000-0001-5380-2486 http://lattes.cnpq.br/0528537500554210

Recebido em: 8 de abril de 2020

Aprovado em: 11 de julho de 2020

RESUMO: Este artigo discute a relação entre o modelo de desenvolvimento em curso no estado do Tocantins e alguns dos impactos que afetam as terras e, consequentemente, a organização social, cosmológica e produtiva do povo indígena Akwẽ-Xerente. Resultado de uma pesquisa realizada no período de 2015 a 2019, as reflexões se embasam na perspectiva da pesquisa etnográfica com os atores e a realidade indígena, além de dados quantitativos para a caracterização do modelo de desenvolvimento em questão. A expansão do agronegócio e a implantação de projetos de infraestrutura como a Usina Hidréletrica (UHE) Luiz Eduardo Magalhães, intensificaram impactos já vivenciados pelo contato prolongado desse povo com a sociedade nacional. Identificamos que há uma relação direta entre esses projetos e mudanças nas formas tradicionais de obter e produzir alimentos, o que causou e tem intensificado a insegurança alimentar entre esse povo. As relações cosmológicas, marcadas pela intercomunicabilidade com os seres que coabitam o território Akwẽ, também têm sido desestruturadas pelo processo analisado. Políticas públicas e projetos voltados para diminuir impactos e promover "desenvolvimento" entre os povos indígenas do estado desconsideram as perspectivas êmicas, as ciências e as cosmologias tradicionais, reproduzindo práticas colonizadoras e reforçando conflitos já estabelecidos historicamente.

Palavras-chave: Desenvolvimento, Tocantins, Impactos, Povo Akwẽ-Xerente

ABSTRACT: This article analyzes the current development model in the state of

${ }^{1}$ Doutora em Antropologia Social pela Universidade Federal do Rio Grande do Sul, professora do Programa de PósGraduação em Desenvolvimento Regional da UFT.E-mail: reipinheiro@uft.edu.br.

${ }^{2}$ Doutor em Antropologia Social pela Universidade de Brasília, professor do Programa de Pós-Graduação em Ciências do Ambiente da UFT. E-mail: hrgracio@hotmail.com. 
Tocantins and some of the impacts that affect the lands and, consequently, the social, cosmological and productive organization of the Akwẽ-Xerente indigenous people. As a result of research carried out in the period from 2015 to 2019, the reflections are based on the perspective of the ethnographic research with the actors and the indigenous reality, as well as quantitative data for the characterization of the development model in question. The expansion of agribusiness and the implementation of infrastructure projects such as the Luiz Eduardo Magalhães Hydropower Plant (UHE) intensified impacts already experienced by the prolonged contact of these people with the national society. We identified a direct relationship between these projects and changes in traditional ways of obtaining and producing food, which has caused and intensified food insecurity among these people. The cosmological relations, marked by the intercommunication with the beings that cohabit the territory Akwẽ also have been deconstructed by the analyzed process. Public policies and projects aimed at reducing impacts and promoting "development" among the indigenous peoples of the state disregard the emic perspectives, the sciences and the traditional cosmologies, reproducing colonizing practices and reinforcing conflicts already established historically.

Keywords: Development, Tocantins, Impacts, Akwẽ-Xerente People

\section{INTRODUÇÃO}

Sentada à sombra de pés de manga, em uma pequena aldeia da Terra Indígena Xerente, uma das lideranças indígenas femininas mais atuantes do estado do Tocantins comenta as grandes mudanças que ocorreram na vida do seu povo (Akwẽ-Xerente), desde a criação do estado, em 1988:

Vivemos cercados pelas plantações de cana. Eles jogam veneno e cai na nossa aldeia, adoece nosso povo. Estão tirando nossa água, os bichos estão morrendo. Antes eu poderia saber se ia chover muito no ano, pois tinha cigarra que avisava. Então eu sabia se devia plantar a roça ou não. Agora as cigarras sumiram e, esse ano, que foi bom de chuva, eu não plantei, pois não teve cigarra para avisar (S. Xerente, fevereiro de 2019).

O processo citado pela liderança é reflexo da intensificação dos projetos agrícolas implementados no Tocantins, que transformaram as Terras Indígenas (Tis) em ilhas verdes cercadas de grãos por todos os lados. Está, ainda, diretamente associado ao modelo de desenvolvimento adotado no estado, que se caracteriza pelos avanços das atividades do agronegócio e de empreendimentos hidrelétricos como a Usina Hidrelétrica Luís Eduardo Magalhães, conhecida regionalmente como UHE Lajeado. As mudanças vividas pelos Akwẽ desafiam a sua sobrevivência e aceleram as transformações e reelaborações culturais, através de um jogo de forças assimétrico e marcadamente colonizador. Este artigo, inicialmente, apresentará alguns dados gerais sobre os povos indígenas no Brasil e no Tocantins, para, posteriormente, trazer informações sobre o avanço das atividades econômicas no estado e, por fim, algumas reflexões sobre o impacto dessas atividades na vida produtiva do povo em questão. Analisamos, ainda, alguns limites da relação do estado com os povos indígenas, considerando as ações voltadas para mitigar impactos, a exemplo das políticas de educação e saúde, além de iniciativas de 
fomento à atividades produtivas.

\section{POVOS INDÍGENAS E TERRAS INDÍGENAS NO TOCANTINS}

Segundo o censo demográfico de 2010, cujos dados sobre as populações indígenas estão em parte sintetizados na tabela abaixo, o Brasil conta com uma população de 896 mil indivíduos que se identificaram como indígenas o que representa $0,47 \%$ da população brasileira, totalizada em 190.755.799 pelo IBGE em 2010. O Tocantins, segundo a mesma fonte, possuía uma população de 1.383 .445 pessoas, o que perfaz $0,72 \%$ da nacional e os indígenas represen$\operatorname{tam} 1,02 \%$ dos residentes no estado, ou seja, 14.118 pessoas.

Conforme exposto abaixo, 57,68\% dos indígenas no Brasil vivem em Terras Indígenas (Tis). Algumas unidades federadas, no entanto, apresentam elevados índices de indígenas residentes fora de Tis, como é o caso de Goiás, Rio de Janeiro, Rio Grande do Norte, entre outros. O Tocantins, na contramão da tendência nacional, apresenta um comportamento distinto: $81,88 \%$ dos indivíduos que se declararam indígenas residem em Tis. O censo de 2010 informa que 3.152 pessoas se identificaram como Xerente ou Akwẽ. Conforme apresentado na tabela 3, as Tis Funil e Xerente, as duas únicas em todo território nacional regularizadas para os Akwẽ, comportam respectivamente 361 e 2361 pessoas. Esses dados nos levam a afirmar que cerca de $86 \%$ dos Akwẽ vivem nas duas Tis. Esse dado é importante para o argumento aqui desenvolvido, pois evidencia a dependência que a população em foco tem em relação aos recursos naturais e à qualidade ambiental de suas terras.

Tabela 1 - Povos Indígenas no Brasil - Dados Demográficos Segundo o Censo de 2010

\begin{tabular}{|c|c|c|c|c|c|c|}
\hline \multirow{2}{*}{ Unidade Territorial } & \multicolumn{5}{|c|}{ Localização do domicílio - Censo Demográfico de 2010.} & \multirow[b]{2}{*}{$\%$} \\
\hline & Total & $\%$ & Em terras indígenas & $\%$ & Fora de terras indígenas & \\
\hline Brasil & 896.917 & 100 & 517.383 & 57,68 & 379.534 & 42,31 \\
\hline Acre & 17.578 & 1,95 & 13.308 & 75,70 & 4.270 & 24,29 \\
\hline Alagoas & 16.291 & 1,81 & 6.268 & 38,47 & 10.023 & 61,52 \\
\hline Amapá & 7.411 & 0,82 & 5.956 & 80,36 & 1.455 & 19,63 \\
\hline Amazonas & 183.514 & 20,46 & 129.529 & 70,58 & 53.985 & 29,41 \\
\hline Bahia & 60.120 & 6,70 & 16.817 & 27,97 & 43.303 & 72,02 \\
\hline Ceará & 20.697 & 2,30 & 2.988 & 14,43 & 17.709 & 85,56 \\
\hline Distrito Federal & 6.128 & 0,68 & - & 0 & 6.128 & 100 \\
\hline Espírito Santo & 9.585 & 1,06 & 3.005 & 31,35 & 6.580 & 68,64 \\
\hline Goiás & 8.583 & 0,95 & 336 & 3,91 & 8.247 & 96,08 \\
\hline Maranhão & 38.831 & 4,32 & 29.621 & 76,28 & 9.210 & 23,71 \\
\hline Mato Grosso & 51.696 & 5,76 & 42.525 & 82,25 & 9.171 & 17,74 \\
\hline Mato Grosso do Sul & 77.025 & 8,58 & 61.158 & 79,40 & 15.867 & 20,59 \\
\hline Minas Gerais & 31.677 & 3,53 & 9.682 & 30,56 & 21.995 & 69,43 \\
\hline Pará & 51.217 & 5,71 & 35.816 & 69,92 & 15.401 & 30,07 \\
\hline Paraíba & 25.043 & 2,79 & 18.296 & 73,05 & 6.747 & 26,94 \\
\hline Paraná & 26.559 & 2,96 & 11.934 & 44,93 & 14.625 & 55,06 \\
\hline Pernambuco & 60.995 & 6,80 & 31.836 & 52,19 & 29.159 & 47,80 \\
\hline Piauí & 2.944 & 0,32 & - & 0 & 2.944 & 100 \\
\hline Rio de Janeiro & 15.894 & 1,77 & 450 & 2,83 & 15.444 & 97,16 \\
\hline Rio Grande do Norte & 2.597 & 0,28 & - & 0 & 2.597 & 100 \\
\hline Rio Grande do Sul & 34.001 & 3,79 & 18.266 & 53,72 & 15.735 & 46,27 \\
\hline Rondônia & 13.076 & 1,45 & 9.217 & 70,48 & 3.859 & 29,51 \\
\hline Roraima & 55.922 & 6,23 & 46.505 & 83,16 & 9.417 & 16,83 \\
\hline Santa Catarina & 18.213 & 2,03 & 9.227 & 50,66 & 8.986 & 49,33 \\
\hline São Paulo & 41.981 & 4,68 & 2.767 & 6,59 & 39.214 & 93,40 \\
\hline Sergipe & 5.221 & 0,58 & 316 & 6,05 & 4.905 & 93,94 \\
\hline Tocantins & 14.118 & 1,57 & 11.560 & 81,88 & 2.558 & 18,11 \\
\hline
\end{tabular}

Fonte: Autores (2018); IBGE, 2010. 
O quadro abaixo apresenta informações fundiárias sobre onze Tis no Tocantins e os povos que as habitam. Essas terras foram regularizadas pela União como Terras Tradicionalmente Ocupadas pelos povos Apinajé, Akwẽ (Xerente), Javaé, Karajá, Krahô-Kanela, Krahô, Tapirapé, Ava-Canoeiro e Guarani. Muito embora constem nos dados da FUNAI, os Tapirapé não possuem na atualidade locais de moradia no Tocantins. Além disso, cabe informar que os Kanela do Araguaia, não citados na tabela, também figuram entre os povos originários do estado. As Tis ocupam aproximadamente 9,3\% da extensão total do Tocantins. A Ti Parque do Araguaia representa 4,86\% de toda a extensão da Unidade Federada e 52,65\% de toda extensão das Tis no Tocantins.

A duas Tis tratadas especificamente nesse estudo, Funil e Xerente, representam respectivamente $0,06 \%$ e $0,6 \%$ da extensão estadual e quando comparadas com as demais Tis perfazem 0,61\% e 6,49\% de suas extensões. Esses dados são importantes quando se considera que essas terras comportam populações culturalmente diferenciadas, que usam e ocupam o espaço de acordo com seus próprios modos.

Tabela 2 - Terras Indígenas no Tocantins

\begin{tabular}{|c|c|c|c|c|c|}
\hline Terra indígena & Etnia & UF & Município & Superfície (ha) & $\begin{array}{l}\text { Situação fun- } \\
\text { diária }\end{array}$ \\
\hline Apinayé & Apinayé & $\mathrm{TO}$ & $\begin{array}{l}\text { Cachoeirinha, Itaguatins, Maurilân- } \\
\text { dia do Tocantins, São Bento do To- } \\
\text { cantins, Tocantinópolis }\end{array}$ & $141.904,21$ & Regular \\
\hline Funil & Xerente & $\mathrm{TO}$ & Tocantínia & $15.703,80$ & Regular \\
\hline Inawebohona & Javaé, Karaja & $\mathrm{TO}$ & Pium, Lagoa da Confusão. & $377.113,57$ & Regular \\
\hline $\begin{array}{l}\text { Javaé/Ava Canoeiro } \\
\text { (Canoanã) }\end{array}$ & Javaé & $\mathrm{TO}$ & Formoso do Araguaia, Sandolândia & 0 & Em estudo \\
\hline Krahô-Kanela & Krahô-Kanela & $\mathrm{TO}$ & Lagoa da Confusão & $7.612,77$ & Regular \\
\hline Kraolândia & Krahô & $\mathrm{TO}$ & Itacajá Goiantins & $302.533,40$ & Regular \\
\hline Parque do Araguaia & $\begin{array}{l}\text { Ava-Canoeiro, Ja- } \\
\text { vaé, Karajá e Tapi- } \\
\text { rapé }\end{array}$ & TO & $\begin{array}{c}\text { Formoso do Araguaia, Lagoa da } \\
\text { Confusão e Pium }\end{array}$ & $1.358 .499,48$ & Regular \\
\hline Taego Ãwa & Ava-Canoeiro & $\mathrm{TO}$ & Formoso do Araguaia & $28.510,00$ & Declarada \\
\hline $\begin{array}{l}\text { Utaria Wyhyna/Iròdu } \\
\text { Iràna }\end{array}$ & Karajá, Javaé & TO & Pium & $177.466,00$ & Declarada \\
\hline Xambioá & Guaraní, Karajá & $\mathrm{TO}$ & Santa Fé do Araguaia & $3.326,35$ & Regular \\
\hline Xerente & Xerente & $\mathrm{TO}$ & Tocantínia & $167.542,11$ & Regular \\
\hline Total & & & & $2.580 .211,68$ & \\
\hline
\end{tabular}

Fonte: BRASIL (FUNAI), 2017.

A última informação mais geral sobre os povos indígenas no Tocantins surge na tabela abaixo que trata dos dados demográficos das Tis tendo como referência o censo de 2010. A Ti Parque do Araguaia comporta $28,17 \%$ da população residente em Tis e as Tis Xerente e Funil abrigam pouco mais de $23 \%$ da população indígena do Estado. 
Tabela 3 - População Residente nas Tis do Tocantins.

\begin{tabular}{l|c|c}
\hline \multicolumn{2}{c}{ População Residente em Ti - Censo Demográfico de 2010 } & População \\
\hline Unidade Territorial & 11.784 & 100 \\
\hline Tocantins & 3.320 & 28,17 \\
\hline Xerque do Araguaia (TO) & 2.361 & 20,03 \\
\hline Kraolândia (TO) & 2.555 & 21,68 \\
\hline Xambioá (TO) & 331 & 2,80 \\
\hline Funil (TO) & 361 & 3,06 \\
\hline Apinayé (TO) & 1.885 & 15,99 \\
\hline Inawebohona (TO) & 230 & 1,95 \\
\hline Krahó-Kanela (TO) & 741 & 6,28 \\
\hline
\end{tabular}

Fonte: Autores (2019); IBGE (2010).

\section{DESENVOLVIMENTO NO TOCANTINS}

O estado do Tocantins apresenta um padrão de desenvolvimento típico para das áreas de expansão de fronteiras. Segundo o IBGE, em 2002 o Produto Interno Bruto (PIB) do Tocantins representou $0,35 \%$ do nacional. Esse percentual subiu para $0,42 \mathrm{em} 2010$ e para 0,45 em 2014.

A tendência registrada nos dados acima é reforçada com as informações disponibilizadas pelo IBGE referente às extensões plantadas. No ano de 2002 a área plantada no Tocantins representava 0,73\% de toda a área plantada no Brasil. Em 2015 esse índice subiu para 1,68\%. Entre os anos de 2002 e 2015 a área plantada com lavouras temporárias no Brasil cresceu $47,6 \%$. No mesmo período o Tocantins registrou um crescimento de $237,29 \%$ na extensão das lavouras temporárias.

As modalidades de lavouras que estão em crescimento no estado também são emblemáticas. Em 2000 as extensões plantadas com a soja representavam 19,96\% de toda área plantada com lavouras temporárias. Esse índice subiu para 69,34\% em 2015, como pode ser observado na tabela abaixo.

Tabela 4 - Área Plantada com Lavouras Temporárias por Produto

\begin{tabular}{|c|c|c|c|c|c|c|c|c|}
\hline $\begin{array}{c}\text { Produto das lavouras temporárias - } \\
\text { Área Plantada (ha). }\end{array}$ & 2000 & $\%$ & 2005 & $\%$ & 2010 & $\%$ & 2015 & $\%$ \\
\hline Abacaxi & 1.878 & 0,64 & 2.055 & 0,29 & 2.683 & 0,40 & 2816 & 0,23 \\
\hline Algodão herbáceo (em caroço) & 0 & 0 & 1.237 & 0,18 & 4.200 & 0,63 & 903 & 0,07 \\
\hline Amendoim (em casca) & 0 & 0 & 1.630 & 0,23 & 3.870 & 0,58 & 2.186 & 0,18 \\
\hline Arroz (em casca) & 148.723 & 51,2 & 199.168 & 28,98 & 137.946 & 20,76 & 119.826 & 10,01 \\
\hline Batata-doce & 0 & 0 & 0 & 0 & 0 & 0 & 1 & 8,35 \\
\hline Cana-de-açúcar & 3.590 & 1,23 & 2.767 & 0,40 & 10.803 & 1,62 & 363.95 & 3,04 \\
\hline Feijão (em grão) & 4.472 & 1,54 & 12.695 & 1,84 & 26.134 & 3,93 & 8.570 & 0,71 \\
\hline Mandioca & 12.043 & 4,15 & 21.500 & 3,12 & 20.869 & 3,14 & 13.847 & 1,15 \\
\hline Melancia & 2.235 & 0,77 & 3.109 & 0,45 & 3.416 & 0,51 & 9.395 & 0,78 \\
\hline Melão & 0 & 0 & 100 & 0,01 & 0 & 0 & 32 & 0,00 \\
\hline Milho (em grão) & 58.625 & 20,20 & 78.182 & 11,37 & 83.229 & 12,53 & 162.078 & 13,54 \\
\hline Soja (em grão) & 57.919 & 19,96 & 355.300 & 51,70 & 352.875 & 53,12 & 830.031 & 69,34 \\
\hline Sorgo (em grão) & 520 & 0,17 & 9350 & 1,360 & 18.170 & 2,73 & 10.914 & 0,91 \\
\hline Tomate & 92 & 0,03 & 25 & 0,00 & 0 & 0 & 0 & 0 \\
\hline Total & 290.097 & 100 & 687.118 & 100 & 664.195 & 100 & 1.196 .994 & 100 \\
\hline
\end{tabular}

Fonte: Autores (2018); IBGE (2010).

Para a pecuária, vamos nos ater aos dados da criação de bovinos. A atividade mostra um comportamento crescente e acima da média nacional. Enquanto no período entre os anos de 2000 e 2015 o rebanho nacional cresceu 26,68\%, o do Tocantins cresceu 36,78\%. Embora o 
índice de crescimento não seja o mesmo observado nas lavouras temporárias, deve-se observar que a participação do Tocantins é elevada e com indicativos de crescimento. Em 2000 o estado respondia por 3,61\% do gado bovino do Brasil e em 2015 esse índice subiu para 3,90\%.

Tabela 5 - Variação do Rebanho Bovino

\begin{tabular}{l|c|c|c|c|c}
\hline \multicolumn{7}{c}{ Variável - Efetivo dos Rebanhos (Cabeças) } \\
\hline \multirow{2}{*}{ Unidade Territorial } & \multicolumn{7}{c}{ Ano de Rebanho - Bovino } \\
\cline { 2 - 6 } & 2000 & 2005 & 2010 & 2015 & $\begin{array}{l}\text { Variação dos Rebanhos entre 2000 e } \\
2015(\%)\end{array}$ \\
\hline Brasil & 169875524 & 207156696 & 209541109 & 215199488 & 26,68 \\
\hline Tocantins & 6142096 & 7961926 & 7994200 & 8401580 & 36,78 \\
\hline $\begin{array}{l}\text { Participação do Tocantins } \\
\text { na Produção do Brasil (\%) }\end{array}$ & 3,61 & 3,84 & 3,81 & 3,90 & \\
\hline Fonte: Autores (2018); IBGE (2010)
\end{tabular}

As atividades da agropecuária, principalmente quando envolvem o ramo do agronegócio, como é o caso do Tocantins, podem ser positivas quando observadas panoramicamente. Todavia, para as populações locais, especialmente para os povos originários, e para o meio ambiente, seus resultados são danosos. Com frequência está associada a conflitos, concentração fundiária, crescimento demográfico, pressão sobre recursos naturais, desmatamento, diminuição significativa da fauna, comprometimento da flora, comprometimento de qualidade da água e impactos culturais. O cenário apontado já se desenhava nas primeiras décadas pós-criação do estado do Tocantins, como mostra Luis Roberto De Paula (2000), ao analisar as relações políticas dos Akwẽ com o estado nascente, e a lógica de modernização agroindustrial presente no programa "Brasil em Ação" e no Programa de Desenvolvimento e Cooperação Nipo-Brasileira (PRODECER):

O território tocantinense, em particular, está colocado como um dos alvos principais do Programa, mas as consequências diretas e indiretas sobre as terras indígenas não são mencionadas. Esses empreendimentos atingem as Tis Xerente, alterando drasticamente seu entorno (Hidrovia Araguaia Tocantins; Ferrovia Norte-Sul; Hidrelétrica do Lajeado; Prodecer III - Programa de Desenvolvimento e Cooperação Nipo-Brasileira para o Desenvolvimento dos Cerrados) e também sua configuração espacial interna, através das tentativas de implementação de obras de infraestrutura tais como a pavimentação de algumas estradas (TO-010; TO-245; TO-450) que cortam as Tis Xerente e a construção de uma ponte sobre o Rio Sono (DE PAULA, 2000, p. 87).

Outra atividade impactante que está em perspectiva para o estado é a mineração. De acordo com a página do Departamento Nacional de Produção Mineral - DNPM, estão tramitando no órgão atualmente 182.521 requerimentos tratando de exploração dos mais diversos recursos minerais no Brasil. Deste total, 17.366 são referentes ao estado do Tocantins. O município de Pedro Afonso, que perfaz o limite norte da Ti Xerente, conta com 176 requerimentos tramitando, Miracema do Norte com 268 e Tocantínia com 128. De acordo com a página do Instituto Socioambiental - ISA (ISA, 2017), a mineração se faz presente em todo entorno das Tis Funil e Xerente. Assim como ocorre com a atividade do agronegócio, a mineração gera pressão fundiária, risco de acidentes, contaminação de cursos hídricos e impactos sobre a fauna e flora.

Em relação à infraestrutura, cabe observar que as Tis Funil e Xerente são cortadas por 
rodovias. Segundo a página do Instituto Chico Mendes - ICMBIO (BRASIL, 2017), estimase que a cada segundo 15 animais são atropelados nas estradas brasileiras, são 1,3 milhões por dia e 475 milhões de animais mortos por ano nas estradas. Essas vias trazem impactos para fauna e, consequentemente, para a atividade de caça. Criam e impõem aos Akwẽ um grande risco de acidentes, facilitam a exploração irregular de recursos naturais dos seus territórios e expõem seus habitantes à circulação de bebidas e drogas.

As usinas hidrelétricas geram grandes impactos para as populações locais, por afetarem fauna, flora, comprometer a qualidade da água da região e por gerarem conflitos fundiários. Além das hidrelétricas já implantadas na bacia do rio Tocantins, a Agência Nacional de Energia Elétrica (ANEEL), informa que estão previstas para o rio Tocantins e seus tributários uma série de empreendimentos. Somente para o rio Sono que define o limite nordeste da Ti Xerente estão previstas seis hidrelétricas, sendo elas: Pequena Central Hidrelétrica - PCH Brejão Jusante e as UHEs Cachoeira da Velha, Monte Santo, Ponte Nova, Rio Sono Baixo e Vermelho (BRASIL, 2017).

\section{OS AKWẼ-XERENTE: IMPACTOS E LIMITES DA RELAÇÃO COM O ES- TADO DO TOCANTINS E OS DESAFIOS DA INTERCULTURALIDADE}

Diante do contexto apresentado, se faz necessário problematizar a categoria Desenvolvimento no seu sentido comumente aceito, a fim de compreender os limites dos projetos de desenvolvimento voltados para os povos indígenas, especificamente para o povo Akwẽ.

Os Akwẽ e são classificados na etnologia como Jê Centrais. Localizam-se no município de Tocantínia a $76 \mathrm{~km}$ de Palmas, (TO). Representam-se por duas metades exogâmicas - Doí (Sol) e Wabirê (Lua). Nesta estrutura os clãs representantes da metade Doí são os Kuzatdekwa (donos do fogo), Kbaritdekwa (donos do algodão), e Kritotdekwa (donos do jogo com a batata assada ou donos da borracha), quanto à metade Wahirê estão incluso os clãs Kroz̧ake, Kreprehi e os $W$ ahiretdekwa. As relações entre os clãs envolvem regras sociais com direitos e deveres recíprocos. Cada clã tem um conjunto de nomes próprios que são passados de pai para filho, de avô paterno para neto ou sobrinho neto. Outro fator que possibilita distinguir as duas metades é a pintura corporal: os Wabirê utilizam traços verticais e os Doí círculos.

Para a cosmologia Akwẽ, o território é um espaço compartilhado por seres visíveis e invisíveis que, assim como os humanos, estabelecem relações sociais e produtivas que devem ser reconhecidas e respeitadas. Para todos esses seres há espaços e alimentos disponíveis, assim como formas de obtê-los. Cada coletividade deve respeitar o que é "de comer" de cada grupo, assim como os espaços de cada um. Cada espécie e espaços naturais têm os seus donos, denominados tdekwas. Estes se relacionam cotidianamente com os humanos. Os tdekwas das águas, por exemplo, aparecem em sonhos, como aponta a narrativa seguinte:

Ontem eu sonhei com o espírito do rio. Fiquei muito assustado, pois quando a gente sonha ele pode estar zangado. Pode acontecer de ficarmos doentes. Quando sonhamos pode ser que ele esteja dizendo que estamos pescando muito, pegando os seus filhos. Então precisamos ficar um tempo sem pescar, para ele ficar calmo novamente e não assustar os nossos sonhos (R. Xerente).

Os tdekwas se comunicam com os Akwẽ quando identificam uma atividade que pode ameaçar o equilíbrio do espaço compartilhado, a exemplo da pesca em excesso. A perspectiva é a 
de que o território é um todo e que o seu equilíbrio depende do respeito a acordos de convivência, muitos deles associados às atividades produtivas como a caça, a pesca, a coleta e a agricultura. Todas essas atividades foram impactadas pela intensificação das atividades econômicas no estado, apresentada anteriormente. Entre as conseqüências mais significativas desses impactos estão as mudanças alimentares, que se tornaram uma das maiores preocupações das lideranças e anciãos, que as associam ao surgimento das doenças crônicas não transmissíveis. Segundo um ancião Xerente, a comida dos "brancos" tem provocado doenças como a diabetes: Cresci comendo sem sal e sem açúcar. Hoje Akwẽ adoece porque como com muito sal e com muito açúcar. Antes a gente comia caça do mato, peixe moqueado, mandioca (S. Xerente).

Rosana Schimidt (2012) descreveu o sistema alimentar Akwẽ, mostrando como ele está estruturado tanto nas possibilidades materiais do cerrado, quanto no sistema cosmológico. Constatou que o aumento do consumo de alimentos processados e o relativo abandono das práticas alimentares tradicionais, bem como a diminuição do plantio entre os Akwẽ é uma das causas diretamente associadas ao modelo de desenvolvimento do estado. Considerando as perspectivas apresentadas é possível deduzir o que significam as mudanças alimentares no contexto em questão, uma vez que em todos os ritos desse povo a comida tem papel fundamental. A festa Dãsipe, por exemplo, é o ritual de nominação das crianças. Só é possível realizála se houver comida suficiente para oferecer aos convidados de outras aldeias, principalmente os cantores e anciãos. O casamento tradicional não pode só pode acontecer com uma espécie de dote alimentar, que é uma generosa porção de farinha para a família do noivo. O ritual funerário depende, também, da oferta de alimentos pelos clãs parceiros, para o pagamento das despesas com o velório.

Os hábitos alimentares de uma população estão ligados aos seus costumes, educação e modo de vida. Comer em todas as sociedades é mais do que simplesmente garantir a subsistência, e um ato simbólico e cultural. Representa um estilo de vida, aprofunda relações familiares e sociais e relacionam-se à cosmologia, formação do corpo, trocas, reciprocidades, ritos, entre outros, diferenciados de acordo com cada grupo. Estudos clássicos sobre antropologia da alimentação consideram o ato alimentar para além do biológico, estabelecendo laços sociais de troca, reciprocidade e hierarquia. Estes estudos apontam que alguns alimentos podem se tornar referências culturais de um povo ou comunidade, compondo um conjunto de tradições identitárias, segundo Maria Eunice Maciel (2005).

Apesar de sabermos que a dinâmica cultural é inerente a todas as sociedades humanas e que a mudança de hábitos é um processo contínuo, o modelo de desenvolvimento econômico apresentado e a pressão destes nas Tis em questão, tem um impacto significativamente negativo, pois provoca desequilíbrios ecológicos e altera as relações tradicionais entre estes indígenas e o ambiente que ocupam. A UHE de Lajeado, ao represar as águas impede, por exemplo, que no Rio Tocantins ocorram as cheias sazonais, que fertilizavam as terras às margens, permitindo o plantio tradicional nas chamadas vazantes, no momento da "seca". Não existindo mais vazantes, não existem mais as roças "de onde se comiam as melancias mais doces", segundo um Akwẽ.

As lideranças apontam que antes da construção da UHE de Lajeado havia cerca de trezentas famílias "vazanteiras" nas Tis Xerente e Funil e que a pesca era abundante. A roça de toco, uma prática condenada pelos órgãos ambientais e sistematicamente combatida, era outra estratégia fundamental de produção de alimentos. R. Xerente afirma que para inibir a prática o estado "prometeu" apoio para mecanizar o plantio nas Tis, mas isso não aconteceu de forma 
suficiente e planejada. É possível ver, em muitas aldeias, sucatas de tratores doados pelo governo estadual, mas que nunca receberam manutenção adequada, assim como também não houve nenhuma preparação técnica efetiva para o processo de "modernização" do plantio. O Programa de Compensação Ambiental Xerente (PROCAMBIX), implementado como contrapartida aos impactos causados pela UHE Lajeado, esteve em vigor no período de 2000 a 2010 e destinou dez milhões de reais para projetos a serem desenvolvidos nas duas Tis.

A administração do PROCAMBIX foi conduzida por representantes do estado, do consórcio de empresas que construiu a UHE Lajeado, de lideranças indígenas e da Fundação Nacional do Índio (FUNAI). Nos moldes dos projetos de compensação, que em geral desconsideram as especificidades culturais dos povos atingidos, intensificou os conflitos já estabelecidos pelo faccionismo clãnico e pelas classes de idade ${ }^{3}$, favorecendo os atores que tinham maiores condições de transitar nas instituições responsáveis pela execução, ou seja, lideranças que tinham curso superior, jovens universitários e funcionários públicos.

Apesar do compromisso de consulta aos anciãos, que se encontram no topo da hierarquia Akwẽ, as dificuldades burocráticas, a falta de compreensão dos trâmites legais e toda a complexidade dos processos que envolvem dinheiro afastaram os anciãos das discussões e decisões relativas à aplicação do recurso. São comuns os relatos dos indígenas sobre as experiências com "os projetos" do programa. Um dos mais famosos refere-se à tentativa de fomentar a criação de galinhas pelas famílias indígenas, quando foram entregues galinhas de granja, com o bico cerrado, ou seja, impossibilitadas de se alimentar livremente. O estranhamento também pode ser explicado pelo fato de que para as cosmologias ameríndias criar animais é uma estratégia produtiva de difícil acomodação, uma vez que cada coletividade tem seu lugar no universo dos seres que compartilham o mesmo território.

Para Eduardo Viveiros de Castro (1986) o pensamento indígena amazônico se sustenta no perspectivismo que pode ser definido como a consciência de que a humanidade é a condição comum a todos os seres (animais e humanos) e que, portanto, haveria uma organização social que também reflete poder, considerando que para a onça, por exemplo, nós seríamos o animal a ser predado. O autor resume, nas palavras seguintes, alguns dos princípios das filosofias ameríndias:

Recordemos, sobretudo que, se há uma noção virtualmente universal no pensamento ameríndio, é aquela de um estado original de indiferenciação entre os humanos e os animais, descrito pela mitologia. Os mitos são povoados de seres cuja forma, nome e comportamento misturam inextricavelmente atributos humanos e animais, em um contexto comum de intercomunicabilidade idêntico ao que define o mundo intra-humano atual. A condição original comum aos humanos e animais não é a animalidade, mas a humanidade (...)Em suma, "o referencial comum a todos os seres da natureza não é o homem enquanto espécie, mas a humanidade enquanto condição" (CASTRO, apud Descola 1986:120).

Para Alcida Rita Ramos (1986), a complexidade do pensamento indígena se apresenta nos mitos. Estes, muitas vezes considerados pelas nossas ciências como manifestações de uma pré-racionalidade, na verdade apontam elementos de uma lógica de intercomunicabilidade en-

\footnotetext{
3 A estrutura social Akwẽ é faccional. Como a maioria das sociedade Jês, a dualidade é o elemento que articula a divisão de poder, marcada constantemente pela disputa entre os clãs. A sociedade Akwẽ pode ser definida como uma gerontocracia, onde os anciãos ocupam o topo da hierarquia do poder decisório.
} 
tre os seres vivos:

As cosmologias indígenas representam modelos complexos, mas integrados dos quais faz parte a sociedade humana. Os mitos são veículos de informação sobre a concepção do Universo, incluindo temas sobre a criação do mundo, a origem da agricultura, as relações ecológicas entre animais, plantas e outros elementos, a metamorfose de seres humanos e animais e vice-versa e de ambos em espíritos de vários tipos e índoles, a razão de ser de certas relações sociais culturalmente importantes e até mesmo o surgimento do - homem branco e a avalanche de fatores desagregadores que o acompanham. (RAMOS, 1986, p.85).

Negreiros (2016) analisou os impactos da UHE Lajeado na cosmologia Akwẽ, apresentando um panorama destes que podem ser sintetizados na incapacidade de diálogo intercultural que caracterizou a implementação da UHE, bem como a gestão de PROCAMBIX. Lima (2017), em pesquisa sobre as transformações no mesmo território após a construção da UHE, aponta que quarenta por cento do recurso do Procambix foi destinado à administração do projeto, e que há um descontentamento generalizado e críticas severas aos gestores.

Constatamos que, oito anos após a finalização do programa, o único projeto que permanece ativo é o da criação de gado. Segundo os próprios indígenas "o gado foi o que sobrou do PROCAMBIX”. Segundo E. Xerente, esse gado ainda existe porque se alimenta do pasto natural das Tis: "a gente deixa o gado livre nos pastos e quando precisamos matamos um para um velório ou alguma festa especial".

Propriedade coletiva das aldeias, as reses são vistas como um problema por alguns anciãos, como podemos constatar na narrativa abaixo:

Akwẽ não gosta de gado, foi com o gado que os fazendeiros tomaram as nossas terras. O gado chegou primeiro e depois eles vinham atrás. Seu eu tivesse uma arma eu matava esse gado que destrói a minha roça. Mas temos que aceitar, pois foi o que sobrou do PROCAMBIX. Akwẽ não sabe lidar com gado (S. Xerente, dezembro de 2018).

Pensando para mitigar impactos, o PROCAMBIX gerou outros impactos, tencionou a já estruturada dualidade social, estabeleceu conflitos entre os anciãos e lideranças indicadas para a gestão e repetiu uma tendência, como aponta Estorniolo (2014), dos projetos de sustentabilidade "não levarem a sério" os conhecimentos indígenas. Faz-se pertinente apontar a necessidade de que os gestores das políticas públicas direcionadas aos povos indígenas considerem a alteridade em questão, com suas cosmologias, lógicas e epistemologias próprias e em toda a sua complexidade.

Para além da experiência do PROCAMBIX, há outros limites na relação do estado do Tocantins com seus povos originários, principalmente no que se refere à promoção de políticas públicas e dos chamados projetos de desenvolvimento. Em primeiro lugar, a educação escolar é a única área inteiramente assumida pelo estado do Tocantins dentro das terras indígenas. Implantada nos primeiros anos de constituição do Tocantins, a proposta é que aos indígenas seja ofertada uma educação bilíngue, que respeite as características culturais de cada povo. O povo Akwẽ Xerente teve contato com o saber escolar sistematizado e consequentemente com a epistemologia ocidental, desde os primeiros aldeamentos indígenas implementados pelos religiosos católicos ainda no século XIX. O Serviço de Proteção ao Índio (SPI), na década de 1940, oferecia aulas de alfabetização e, a partir da década de 1950, há uma significativa atuação

PRACS: Revista Eletrônica de Humanidades do Curso de Ciências Sociais da UNIFAP https://periodicos.unifap.br/index.php/pracs ISSN 1984-4352 Macapá, v. 13, n. 2, p. 131-144, jul./dez. 2020 
dos missionários batistas entre os Xerente (GIRALDIN \& MELO, 2012). A intenção principal destes missionários era traduzir os textos bíblicos para a língua Akwẽ a fim de evangelizá-los, esse trabalho, em contrapartida, contribuiu para o desenvolvimento da escrita da língua. Ao assumir a educação indígena o estado ofereceu alguns cursos de formação para professores indígenas o que fez com que muitos deles passassem a lecionar nas suas aldeias. Foram construídas muitas escolas na área Akwẽ, desconsiderando a tradição de mobilidade que os caracteriza, bem como o faccionismo clânico, marcado pela estruturação constante de novas aldeias e mudança de local. Como resultado há muitas escolas abandonadas na área, uma vez que, construídas em tijolos, não podem ser removidas junto com as famílias.

A saúde Indígena, outra área prioritária da atuação do estado, é de responsabilidade da Secretaria de Saúde Indígena (SESAI), que foi criada pela União em 2010 para substituir o atendimento que era responsabilidade da FUNASA. A SESAI foi instituída como um subsistema do Sistema Único de Saúde (SUS), para atuar exclusivamente na atenção básica, transferindo a responsabilidade da atenção especializada para o SUS. Isso significa que estados e municípios devem acolher os indígenas na rede de saúde, dispensando a eles os cuidados referentes às especialidades. Em pesquisas realizadas na área constatamos que há inúmeras resistências por parte dos municípios em acolher e atender os indígenas nas unidades e hospitais regionais e também nos hospitais de Palmas. A criação da SESAI não foi acompanhada de uma sensibilização para o acolhimento aos indígenas e permanece a compreensão de que caberia exclusivamente à união essa responsabilidade.

Importante ressaltar que apesar da uníssona tese de que as cidades próximas às terras indígenas são prejudicadas e tem os seus serviços públicos sobrecarregados pelos indígenas (SILVA, 2015), boa parte da arrecadação desses municípios vem do Imposto sobre Circulação de Mercadorias e Serviços - ICMS e, para os municípios que fazem parte do programa, do ICMS ecológico, como mostram Demarchi \& Santos (2015), que desconstroem o argumento de que as terras indígenas impedem o desenvolvimento das cidades, bem como os indígenas sobrecarregam os serviços de saúde, entre outros:

Em verdade, os "latifúndios dos índios" são produtivos do ponto de vista da arrecadação do ICMS Ecológico, conforme a legislação do Estado do Tocantins. O contraponto assim delineado desafia a população e principalmente a seus representantes políticos a operar um redimensionamento da questão indígena no contexto local. Se as terras indígenas, pelo fato de contribuírem com a conservação ambiental, asseguram uma importante parcela da arrecadação do ICMS Ecológico para o erário público municipal, os povos indígenas deixam de ser considerados como virtuais inimigos (detentores de terras improdutivas) e passam a ser potenciais aliados de um projeto de desenvolvimento que inclua princípios de conservação ambiental, sustentabilidade dos territórios indígenas e seu entorno, além da promoção e proteção a seu modo de vida e a sua cultura (DEMARCHI \& SANTOS,2015, p. 157).

Para além das políticas públicas de saúde e educação, as dificuldades dialógicas entre os poderes locais, sociedade civil, instituições acadêmicas, organizações não governamentais e os povos indígenas também se manifestam nos projetos e programas de desenvolvimento implementados. Apresentamos como exemplo as várias tentativas de fomentar o cultivo de hortas comunitárias por parte de Instituto de Desenvolvimento Rural do estado (RURALTINS), (TOCANTINS, 2014), nas Tis do estado. No caso dos Akwẽ existe uma forte resistência ao consumo de hortaliças. Apesar da intensa transformação alimentar dentro da área, há uma 
rejeição "às folhas", como muitos se referem, pelo fato de serem alimentos da preferência de alguns animais de pequeno porte e rastejantes, como lagartos. A necessidade do cuidado com as hortas é, assim, desmotivada por essa rejeição. São muitos os projetos de hortaliças que começaram e depois foram abandonados pelos indígenas ao longo dos anos.

Diante do cenário apresentado, ressaltamos que a perspectiva de desenvolvimento presente nas ações e projetos do estado, voltados para os povos indígenas, nega a diferença que os constitui, não instituindo canais de diálogo intercultural e adotando a idéia de que o "desenvolvimento" é imprescindível e inquestionável. Tanto Arthuro Escobar (2007), quanto Rodolfo Stavenhagen (1984), ao submeterem a categoria desenvolvimento a uma análise histórica crítica, nos ajudam a compreender como ela alcançou o status de "um movimento" necessário aos chamados países de Terceiro Mundo.

O trabalho Arthuro Escobar (2007) desconstrói, simultaneamente, as categorias Terceiro Mundo e Desenvolvimento, a partir da crítica à narrativa universalista citada. $\mathrm{O}$ autor confronta as teses coloniais que sustentam a perspectiva em questão, centrada nos valores e interesses dos países ricos e do mercado global, que se desdobraram em políticas econômicas desenvolvimentistas e intervencionistas, no período pós-segunda guerra mundial. Essa perspectiva revela, ainda, elementos da dicotomia "modernidade" e "tradição", fundamental nos debates sobre a relação entre desenvolvimento, populações tradicionais e povos indígenas. A narrativa universalista do desenvolvimento apresentava como inevitável o desaparecimento de formas sociais ancestrais, classificadas como manifestações irracionais, que seriam superadas pela expansão e modernização capitalistas. Para Rodolfo Stavenhagem (1984) a tese comumente aceita de que os povos indígenas seriam um entrave ao desenvolvimento revela a prevalência de uma perspectiva que compreende suas formas de vida como resquícios de um passado pré-racional, associado a uma possível pré-história da humanidade.

$\mathrm{Na}$ mesma direção Paul Little (2002) afirma que as teorias do desenvolvimento desconsideraram as questões étnicas, ou da etnicidade, na construção dos parâmetros que orientaram as análises sobre os entraves ou condições favoráveis ao desenvolvimento no século XX. Para Batalla(1982), os processos de desenvolvimento dos povos indígenas devem ser orientados pelo viés étnico, uma vez que cada povo tem uma história e potencial cultural que devem ser reconhecidos e legitimados. O mesmo autor defende o etnodesenvolvimento como uma possibilidade de reconhecer, valorizar e respeitar os saberes e as estratégias indígenas.

\section{CONSIDERAÇÕES FINAIS}

Ao incorporar as discussões apresentadas, propomos que o protagonismo indígena no que se refere à autossustentabilidade econômica e social, implica, consequentemente, em reconhecer as epistemologias que orientam as formas de ocupar e pensar os territórios que ocupam. Se os processos permanecem negando a esses povos a prerrogativa de direcionar, de acordo com suas cosmologias, os rumos das relações com a sociedade nacional, não haverá espaço para um desenvolvimento equânime que contemple a diversidade cultural e menos ainda para etnodesenvolvimento, que necessariamente, deve contemplar as especificidades epistemológicas e socioambientais das populações locais.

É importante afirmar que não é possível propor e executar projetos gerais e iguais para todos os indígenas brasileiros. As políticas de estado devem reconhecer a sociodiversidade indígena e a partir desse ponto estabelecer a escutas necessárias. A imagem romantizada e 
exotizada do indígena ecológico, preso a uma natureza idílica, por outro lado, só nos distancia dos indígenas reais e em nada contribui para que os diálogos interculturais se estabeleçam e sejam efetivos.

Acrescentamos a necessidade de considerar as ciências indígenas para a produção de conhecimento sobre as possibilidades produtivas e sustentáveis dos seus territórios, promovendo um processo que Paul Little (2002) chamou de intercientificidade, onde seria possível relacionar saberes sobre ecologia, produção de alimentos, saúde, educação entre outros, de maneira que aos conhecimentos tradicionais sejam garantidos os direitos e reconhecimentos legais. Em síntese para considerar o etnodesenvolvimento no horizonte dos projetos voltados para os povos indígenas é preciso estruturar processos de escuta e consulta aos indígenas, valorizar e considerar seus saberes, suas estruturas sociais e de poder, a fim de que eles exerçam sua capacidade social de construir "seu futuro, aproveitando suas experiências históricas e os recursos reais e potenciais de sua cultura, de acordo com projetos definidos segundo seus próprios valores e aspirações”. (BATALLA, et AL, 1982, p. 220).

Finalmente sugerimos que essa é urgente a necessidade de construir um diálogo efetivo entre o Estado brasileiro e os povos indígenas, uma vez que estamos diante de agravos de saúde que tendem a repetir a história de extermínios que marca relação. É preciso considerar o protagonismo indígena e valorizar as possibilidades produtivas, na contramão do que tem sido feito pelo Estado, mantendo a perspectiva de que poderíamos ensinar a esses povos como plantar e como lidar o seu território. Nesta direção a categorias etnodesenvolvimento abre possibilidades dialógicas entre os universos em questão e nos permite uma maior aproximação das lógicas indígenas.

\section{REFERÊNCIAS}

ABRASCO - Associação Brasileira de Pós-Graduação em Saúde Coletiva. I Inquérito Nacional de Saúde e Nutrição dos Povos Indígenas, $\mathrm{n}^{\circ} 7$ (Análise de dados) [relatório final]. Rio de Janeiro: ABRASCO; 2009.

ARAÚJO, R. N. Os Territórios, os modos de vida e as cosmologias dos indígenas Akwe-Xerente, e os impactos da UHE de Lajeado. 2016. 212f. Tese (Programa de PósGraduação em Geografia). PPG/UFC, Fortaleza, CE, 2016.

BATALLA, G. B et AL. America Latina: etnodesenvolvimento, etnocídio. Costa Rica: Flacso, 1982.

BRASIL. Agência Nacional de Energia Elétrica. Relatório de Acompanhamento de Empreendimentos de Geração. Disponível em: < http://www.aneel.gov.br/sala-de-imprensaexibicao-2/-/asset_publisher/zXQREz8EVlZ6/content/aneel-divulga-relatorio-de-acompanhamento-de-empreendimentos-de-geracao/656877? inheritRedirect $=$ false $>$. Acesso em: 06 de junho de 2019.

Constituição (1988). Constituição da República Federativa do Brasil. Brasília, DF: Senado Federal: Centro Gráfico, 1988. 292 p.

Instituto Chico Mendes de Conservação da Biodiversidade - ICMBIO. A cada segundo 15 animais silvestres morrem atropelados. Disponível em: < http://www.icmbio.gov.br/portal/ultimas-noticias/4-destaques/4944-a-cada-segundo-15-animais-silvestres-morrem-atropelados-no-Brasil\%3E > . Acesso: 06 de junho de 2019

- Instituto Brasileiro de Geografia e Estatística - IBGE. Censo Demográfico 2010 - 
Características Gerais da População. Resultados da Amostra. Disponível em: <https://sidra.ibge.gov.br/home/pimpfbr/brasil>. Acesso em 06 de junho de 2019.

Ministério das Minas e Energias. DNPM. Disponível em:. <https:// sistemas.dnpm. gov.br/SCM/site/admin/dadosProcesso.aspx>.Acesso em: 06 de junho de 2019

- Ministério da Justiça. FUNAI. Índios no Brasil e Terras Indígenas. Disponível em: <http://www.funai.gov.br/index.php/indios-no-brasil/terras-indigenas $>$. Acesso em: 06 de junho de 2019

CASTRO, E.V. Os pronomes cosmológicos e o perspectivismo ameríndio. CASTRO, E.V. Os pronomes cosmológicos e o perspectivismo ameríndio. Mana, Rio de Janeiro, out. 1996.

DEMARCHI, A. SANTOS, O. BANDEIRA, M.S. G. ICMS Ecológico e Terras Indígenas no Tocantins: o caso Apinajé. In: DA SILVA, R. P. Povos Indígenas do Tocantins: desafios contemporâneos. 1. ed. Palmas, TO: Nagô, 2015. V. 01. 253p.

DE PAULA, L. R. Dinâmica faccional Xerente: esfera local e processos sociopolíticos. 2000. 352

f. Dissertação (Mestrado em Antropologia Social). PPGAS/USP, São Paulo, SP, 2000.

ESTORNIOLO, M. Laboratórios na floresta : os Baniwa, os peixes e a piscicultura no Alto Rio Negro. Brasília : Paralelo 15, 2014. 549 pp.

GIRALDIN, O. MELO, V.M.C. Os Akwe-Xerente e a busca pela domesticação da escola. Tellus, Campo Grande, ano 12, n. 22, p. 177-199, jan/jun.2012.

LIMA, L.G.B. Os Akwẽ-Xerente no Tocantins: território indígena e as questões socioambientais. 2016. 320 f. Tese (Programa de Pós-Graduação em Geografia Humana). PPGGH/USP, São Paulo, SP, 2016.

LITTLE, P. E. Etnodesenvolvimento local: autonomia cultural na era do neoliberalismo global. Tellus, Campo Grande, v. 2, n. 3, p. 33-52, 2002.

MACIEL; Maria Eunice. Identidade cultural e alimentação. In: CANESQUI, A. M. GARCIA, R.W.D. Antropologia e Nutrição: um diálogo possível. Rio de Janeiro: Fiocruz, 2005. V.1. 306 p.

ROCHA, T.S; DA SILVA, R.P; NASCIMENTO, M.M. Changing dietary habits among Akwen Xerente. Revista da Escola de Enfermagem da USP (Online), v. 50, p. 96-100, 2015. SILVA, Reijane Pinheiro da. Entre mundos e entre saberes: os desafios epistemológicos dos alunos Akwen Xerente na Universidade Federal do Tocantins. Interação (UFG. Impresso), v. 40, p. 537-555, 2015.

SOUZA LIMA, A.C; BARROSO-HOFFMANN, M. (orgs.). 2002. Etnodesenvolvimento e politicas públicas: bases para uma nova política indigenista. Rio de Janeiro: Contra Capa Livraria. 3 vols. 160 pp.

STAVENHAGEN, R. Etnodesenvolvimento: uma dimensão ignorada no pensamento desenvolvimentista. Anuário Antropológico 84. Rio de Janeiro: Tempo Brasileiro,1985.

TOCANTINS. Instituto de Desenvolvimento Rural. Governo do Estado implanta hortas comunitárias em aldeias indígenas - Palmas: 2014. https://ruraltins.to.gov.br/noticia/2014/5/26/governo-do-estado-implanta-hortas-comunitarias-em-aldeias-indigenas/ 